\title{
$\beta$-elemene inhibits the proliferation of T24 bladder carcinoma cells through upregulation of the expression of Smad4
}

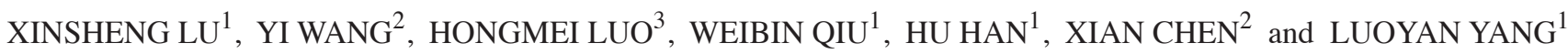 \\ ${ }^{1}$ Department of Urology, The Second Xiangya Hospital of Central South University, Changsha, Hunan 410011; \\ ${ }^{2}$ Department of Urology, Second Affiliated Hospital of University of South China; \\ ${ }^{3}$ Department of Histology and Embryology, University of South China, Hengyang, Hunan 421001, P.R. China
}

Received July 6, 2012; Accepted November 5, 2012

DOI: $10.3892 / \mathrm{mmr} .2012 .1206$

\begin{abstract}
. $\beta$-elemene, a non-cytotoxic antitumor reagent, inhibits the growth, proliferation and DNA synthesis of multiple types of malignant cells, resulting in the apoptosis or suppressed vascularization of tumors. $\beta$-elemene is also able to enhance the immunogenicity of the tumor cells and ameliorate systematic cellular immunity in the tumor-bearing body. Moreover, $\beta$-elemene has the advantages of high efficiency, safety and low possibility of drug tolerance over other antitumor agents used in antitumor treatment. Therefore, $\beta$-elemene has great potential in clinical applications. However, the mechanism of $\beta$-elemene antitumor activity is largely unknown. The aim of this study was to investigate whether $\beta$-elemene is able to repress the proliferation of T24 bladder carcinoma cells through regulation of the expression of the tumor suppressor gene, Smad4. Results of a methylthiazolyl tetrazolium (MTT) assay indicated that the proliferation of T24 cells was repressed by $\beta$-elemene in a time- and concentration-dependent manner. The lowest concentration of $\beta$-elemene to inhibit cell survival by $>50 \%$ was determined using $\mathrm{IC}_{50}$ software. Microscopic observation also demonstrated the potential of $\beta$-elemene to induce the apoptosis of cancer cells. Western blot and RT-PCR analyses revealed that the expression of the $\mathrm{Smad} 4$ protein and mRNA was upregulated by treatment with $\beta$-elemene. Our results revealed that $\beta$-elemene was able to upregulate the expression of Smad4 in tumor cells to inhibit the proliferation of these cells.
\end{abstract}

\section{Introduction}

Elemene is an effective antitumor agent extracted from Curcuma aromatica Salisb. of the Zingiberaceae plant family, which is used as a national class II noncytotoxic

Correspondence to: Professor Luoyan Yang, Department of Urology, The Second Xiangya Hospital of Central South University, No. 139 Renmin Zhong Road, Changsha, Hunan 410011, P.R. China E-mail: luoyany@yahoo.com

Key words: $\beta$-elemene, Smad4, human bladder cancer antitumor agent in China. The main ingredient of elemene is 1-methyl-1-ethylene-2,4-diisopropyl cyclohexane (C15H24), which is also known as $\beta$-elemene. $\alpha$ - and $\gamma$-elemene, as well as other terpene compounds, are also components of elemene, and all are effective antitumor agents. $\beta$-elemene has been investigated in numerous studies and has demonstrated potent ability to inhibit the growth of and kill multiple types of malignant cells in vitro and in vivo $(1,2)$. Therefore, $\beta$-elemene is intensely investigated as an antitumor agent at present.

TGF- $\beta$ signaling pathways are able to regulate numerous cellular processes, including growth, development, division, death, oncogenesis and tumor progression, and Smad proteins are involved in these processes $(3,4)$ Smad proteins participate in the signal transduction of the TGF family directly in the form of adjuvant activators downstream of the TGF- $\beta$ ligand (5-7). Smad4 was first identified by Lagna in 1996 and was recognized as a candidate tumor suppressor gene (8). Smad4 plays a role in Smad-mediated signal transduction as the co-mediator of all Smads (9).

Our study found that $\beta$-elemene effectively inhibited the proliferation of T24 cells in a concentration- and time-dependent manner, and induced the apoptosis of T24 cells by upregulating the expression of the Smad4 gene, which provided a theoretical basis for the use of $\beta$-elemene in the treatment of bladder cancer.

\section{Materials and methods}

Reagents. $\beta$-elemene was purchased from Jin Gang Pharmaceutical Co. (Dalian, China). Trypsin was purchased from Bi Yuntian (Haimen, China). Dimethyl sulfoxide (DMSO) was purchased from Sheng Gong Biological Engineering Co. (Shanghai, China). Methylthiazolyl tetrazolium (MTT) was purchased from Sigma (St. Louis, MO, USA). Agents for primer synthesis, DEPC, ethidium bromide and RNase-free water were purchased from Sheng Gong Biological Engineering Co.

Cell culture. The bladder cancer cell line T24 was purchased from the cell repository of Xiangya Medical College of Zhongnan University. The cells were cultured in RPMI-1640 medium (Gibco, Carlsbad, CA, USA) with $10 \%$ fetal calf serum (Sijiqing Co., Hangzhou, China) at $37^{\circ} \mathrm{C}$ with $5 \% \mathrm{CO}_{2}$ and $95 \%$ humidity. 
MTT assay. T24 cells in the exponential growth phase were inoculated into a 96-well plate, with $10^{3}-10^{4}$ cells and $200 \mu \mathrm{l}$ medium in each well. After $24 \mathrm{~h}$ of culturing, 0, 0.004, 0.008, $0.01,0.02,0.04,0.06$ or $0.08 \mathrm{mg} / \mathrm{ml}$ of $\beta$-elemene was added to the culture. The cells were cultured for a further 24,48 or $72 \mathrm{~h}$, and the absorbance at $570 \mathrm{~nm}\left(\mathrm{OD}_{570}\right)$ of each well was detected using an enzyme-linked immunoassay apparatus (model DG3022, Fourth Military Medical University and the state-owned East Electronic Tube Factory, China). Each concentration of $\beta$-elemene was used to treat the cells in four wells, and the $\mathrm{OD}_{570}$ of untreated cells was normalized as 0 .

The survival rate of the T24 cells was calculated by dividing the $\mathrm{OD}_{570}$ value of the experimental group by that of the control group. $\mathrm{IC}_{50}$ software (independently researched and developed by our own laboratory) was used to calculate the concentration of $\beta$-elemene for each treatment time that would inhibit cell growth by $50 \%$.

Microscopic observation. T24 bladder carcinoma cells in the exponential growth phase were digested and inoculated into six-well plates with $5 \times 10^{5}$ cells per well. The cells were combined with $2 \mathrm{ml}$ substrate in each well and kept in an incubator at $37^{\circ} \mathrm{C}$ with $5 \% \mathrm{CO}_{2}$ and saturated humidity for $24 \mathrm{~h}$. After the cells in each well had become adherent, they were separated into two groups. The control group was untreated and the test group was incubated with $0.02 \mathrm{mg} / \mathrm{ml} \beta$-elemene until cell survival was inhibited by $\geq 50 \%$. The cells were incubated for a further 24,48 or $72 \mathrm{~h}$ and then subjected to observation under an inverted microscope.

$R T-P C R$. Total RNA was extracted using the TRIzol reagent (Invitrogen, Carlsbad, CA, USA) from the control cells and the cells treated with $0.02 \mathrm{mg} / \mathrm{ml} \beta$-elemene for 24,48 or $72 \mathrm{~h}$. For each sample, the ratio $\mathrm{OD}_{260} / \mathrm{OD}_{280}$ was $1.70-1.95$ by ultraviolet spectrophotometric analysis and the purity of the RNA was determined by electrophoresis. cDNAs were obtained using an AMV reverse transcriptional kit (Promega Corporation, Madison, WI, USA) according to the manufacturer's instructions. The mRNA levels of Smad4 were analyzed by PCR, and $5 \mu \mathrm{l}$ of the PCR product was separated using $2 \%$ agarose gel containing $0.5 \mathrm{mg} / \mathrm{ml}$ ethidium bromide. The expression of $\beta$-actin mRNA was detected as an internal control. Images of the gel were captured with an EC3 System gel image analyzer (UVP, Upland, CA, USA). Each experiment was repeated at least 3 times.

Western blot. Untreated cells and cells that had been treated with $0.02 \mathrm{mg} / \mathrm{ml} \beta$-elemene for 24,48 or $72 \mathrm{~h}$ to reach $\geq 50 \%$ inhibition of cell survival were collected. The total protein was extracted and then quantified by the BCA method (Pierce Biotechnology, Inc. (Rockford, IL, USA). An equal amount of protein was subjected to $6 \%$ SDS-PAGE. After electrophoretic separation, the proteins were transferred onto a polyvinylidene fluoride (PVDF) membrane (Bi Yuntian). The membrane was then incubated with Smad4 monoclonal antibody (Santa Cruz Biotechnology, Inc., Santa Cruz, CA, USA) and $\beta$-actin monoclonal antibody (Zhongshan Jinqiao, Beijing, China). After incubating with anti-mouse or anti-rabbit secondary antibodies (Santa Cruz Biotechnology, Inc.) and rinsing with buffer solution (Bi Yuntian), the protein bands were developed by chromogenesis with a DAB luminescence kit (Bi Yuntian). The signals of the bands were digitally scanned and quantified by gray scale scanning, and were analyzed to determine the gray scale (Value V) of every product using Alpha Imager 2200 software (Alpha Innotech Corp., San Leandro, CA, USA). The relative expression levels of protein from each sample were calculated by dividing Value $\mathrm{V}$ of the target protein by that of the corresponding $\beta$-actin.

Statistical analysis. Data are presented as the mean \pm standard deviation (SD). Variance analysis was performed using one-way analysis of variance (ANOVA) with SPSS 13.0 software (SPSS, Inc., Chicago, IL, USA). The LSD t-test was performed for the comparison of means between the treatment and control groups, and the SNK-q test was used for the comparison of means between the treatment groups. $\mathrm{P}<0.05$ was considered to indicate a statistically significant result.

\section{Results}

$\beta$-elemene decreased the survival rate of T24 cells. To determine the survival rate of the T24 bladder carcinoma cells following treatment with various concentrations of $\beta$-elemene for different times, the $\mathrm{OD}_{570}$ values of the cells following treatment with $0.004,0.008,0.01,0.02,0.04,0.06$ or $0.08 \mathrm{mg} / \mathrm{ml}$ of $\beta$-elemene for 24,48 and $72 \mathrm{~h}$ were measured by MTT assay. The results revealed that the survival rates of the T24 cells treated with $<0.02 \mathrm{mg} / \mathrm{ml} \beta$-elemene for 24,48 or $72 \mathrm{~h}$ were $>60,45$ and $30 \%$, respectively, while the survival rates of the cells treated with $>0.02 \mathrm{mg} / \mathrm{ml}$ of $\beta$-elemene were $<30,25$ and $23 \%$ respectively (Fig. 1A). Therefore, the cell survival rate was inversely correlated with the concentration of $\beta$-elemene. One-way ANOVA showed that the P-values between the groups of cells treated with different concentrations of $\beta$-elemene for 24,48 and $72 \mathrm{~h}$ were $0.065,0.820$ and 0.117 , respectively, all of which were $>0.05$, indicating the general homogeneity of variance in OD values between different groups and the control (a total of 8 groups). Moreover, when the cells were treated with $\beta$-elemene for 24 and $48 \mathrm{~h}$, significant differences were observed in the OD values between any two groups treated with different concentrations of $\beta$-elemene or the control group $(\mathrm{P}<0.05)$. However, when the cells were treated for $72 \mathrm{~h}$, there were a few exceptions. For example, the P-value for the comparison of ODs between the 0.02 and $0.04 \mathrm{mg} / \mathrm{ml}$ treatment groups was 0.07 , between the 0.01 and $0.02 \mathrm{mg} /$ $\mathrm{ml}$ treatment groups was 0.294 , and between the 0.008 and $0.01 \mathrm{mg} / \mathrm{ml}$ treatment groups was 0.17 . Therefore, the cell survival rate was inversely correlated with the concentration of $\beta$-elemene used to treat the cells.

By analyzing the OD values of cells treated with the same concentration of $\beta$-elemene for different time periods, we found that the differences in the OD values in different time periods between any two groups were also statistically significant $(\mathrm{P}<0.05)$. The $\mathrm{OD}_{570}$ values of the cells decreased as the treatment time with $\beta$-elemene increased, suggesting that the survival rate of the T24 cells was also inversely correlated with the incubation time. The $\mathrm{IC}_{50}$ values of the T24 cells treated with $\beta$-elemene were calculated by $\mathrm{IC}_{50}$ software that we independently developed in our own laboratory, and the $\mathrm{IC}_{50}$ values for 24,48 and $72 \mathrm{~h}$ treatment were $0.015,0.010$ and 
A

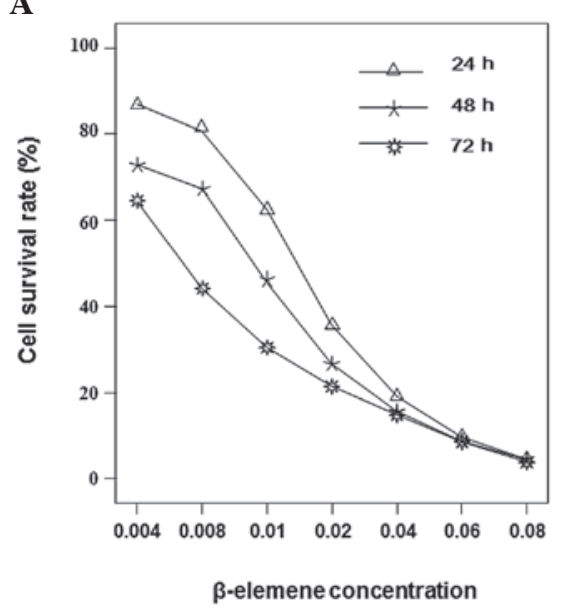

B

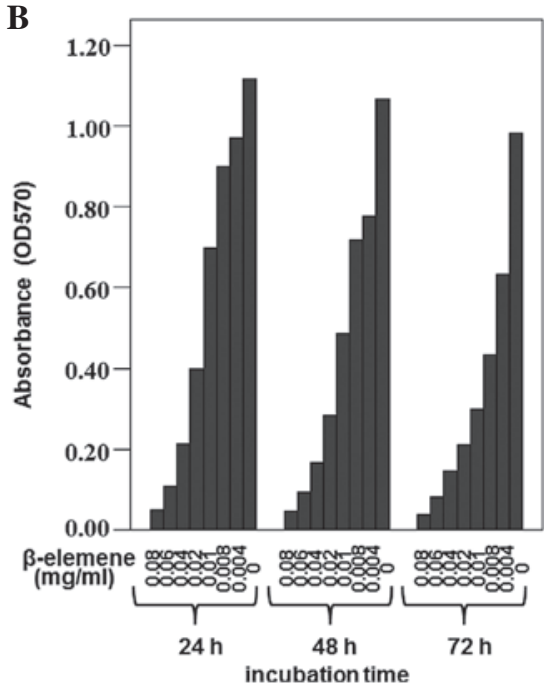

Figure 1. Methylthiazolyl tetrazolium (MTT) assay of T24 cells following incubation with $\beta$-elemene. (A) The T24 cells were treated with $0.004,0.008,0.01$, $0.02,0.04,0.06$ or $0.08 \mathrm{mg} / \mathrm{ml} \beta$-elemene for 24,48 or $72 \mathrm{~h}$. The survival rate of the cells was detected by MTT assay at $570 \mathrm{~nm}\left(\mathrm{OD}_{570}\right)$. $(\mathrm{B}) \mathrm{The} \mathrm{IC}_{50}$ values of the $\mathrm{T} 24$ cells treated with $\beta$-elemene were calculated using $\mathrm{IC}_{50}$ software.
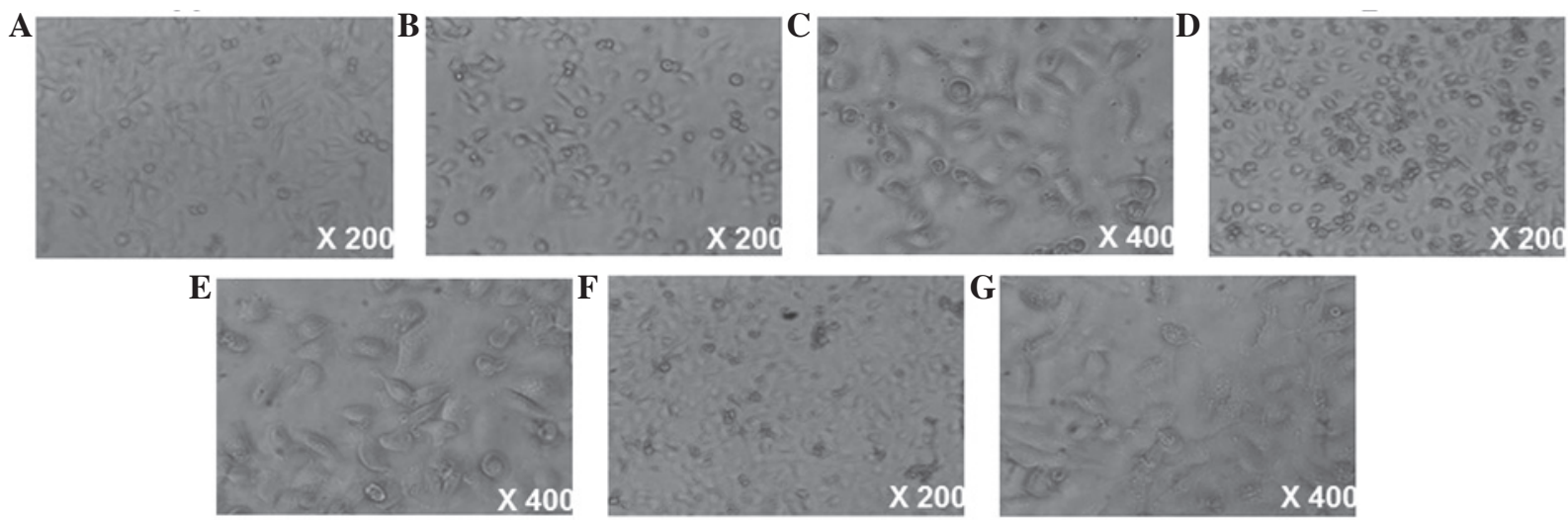

Figure 2. Microscopic observation of T24 cells following $\beta$-elemene treatment. (A) Normal bladder carcinoma T24 cells in the exponential growth phase (x200). T2 4 cells treated with $0.02 \mathrm{mg} / \mathrm{ml} \beta$-elemene (B) for $24 \mathrm{~h}$, showing round or elliptical shapes and reduction in size (x200); (C) for $24 \mathrm{~h}$ ( $\mathrm{x} 400$ ); (D) for $48 \mathrm{~h}$, showing a suspending state (x200); (E) for $48 \mathrm{~h}$, showing the disappearance of intracellular structures, lysis and germination (x400); (F) for $72 \mathrm{~h}$, showing suspension, apoptosis or lysis (x200); and (G) for $72 \mathrm{~h}$, the majority of which show lysis and loss of normal morphology (x400).

$0.006 \mathrm{mg} / \mathrm{ml}$, respectively (Fig. 1B). According to the above analysis, the lowest concentration of $\beta$-elemene that inhibited cell survival by $>50 \%$ for different treatment times, i.e., $0.02 \mathrm{mg} / \mathrm{ml}$ for $24 \mathrm{~h}$, was chosen for following studies.

$\beta$-elemene treatment markedly changed the morphology of T24 cells. We investigated the morphology of the T24 cells following $\beta$-elemene treatment. Adhesion of the majority of the cells was observed under an inverted microscope at $12 \mathrm{~h}$ post-passage. The cells extended and enlarged to form spindles, triangles, fibrous shuttles or polygons, with an oval nucleus in the center containing 2-5 nucleoli (Fig. 2A). These cells grew well, appeared homogenous under the optical microscope and were highly transparent. The untreated cells proliferated rapidly and multiplied markedly within $24 \mathrm{~h}$ to enter the logarithm growth period. However, the cells treated with $0.02 \mathrm{mg} / \mathrm{ml} \beta$-elemene for $24 \mathrm{~h}$ showed a tendency for suspended growth with a decreased rate of attachment, and some of the cells became round, elliptical or irregular in shape (Fig. 2B and C). Cells treated for $48 \mathrm{~h}$ showed increased percentages of round cells, with some cells germinated along the cellular surface, decreased in size with condensed cytoplasm and a clearly decreased cytoplasm to nucleus ratio, which indicated that the process of apoptosis had been initiated. Moreover, the percentages of suspended or raised single-layer cells increased and some cells collapsed into fragments (Fig. 2D and E). When the cells were incubated with $0.02 \mathrm{mg} / \mathrm{ml} \beta$-elemene for $72 \mathrm{~h}$, most of the cells lost their normal morphology, and numerous suspended cells appeared, with fragments in the cellular membrane and condensed nucleolus (Fig. 2F and G). These results indicated that the morphology of the T24 cells changed as the duration time of the $\beta$-elemene treatment varied. In summary, when the incubation time increased, the cells were more likely to become round or elliptical, followed by nuclear condensation, cellular germination, appearance of apoptotic bodies, and eventually the rupture of the cell membrane, cell suspension and fragmentation. 


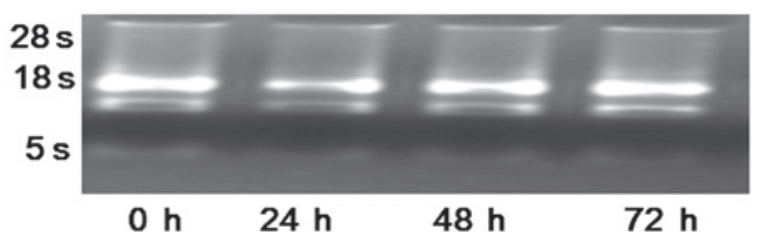

Figure 3. Agarose gel separation of total RNA extracted from T24 cells. T2 4 cells were untreated or treated with $0.02 \mathrm{mg} / \mathrm{ml} \beta$-elemene for 24,48 or $72 \mathrm{~h}$ and total RNA was extracted. The $\mathrm{OD}_{260} / \mathrm{OD}_{280}$ ratio of the RNA was 1.70-1.95. The RNA was separated using $1 \%$ agarose gel, and the $28 \mathrm{~S}, 18 \mathrm{~S}$ and $5 \mathrm{~S}$ bands are indicated.

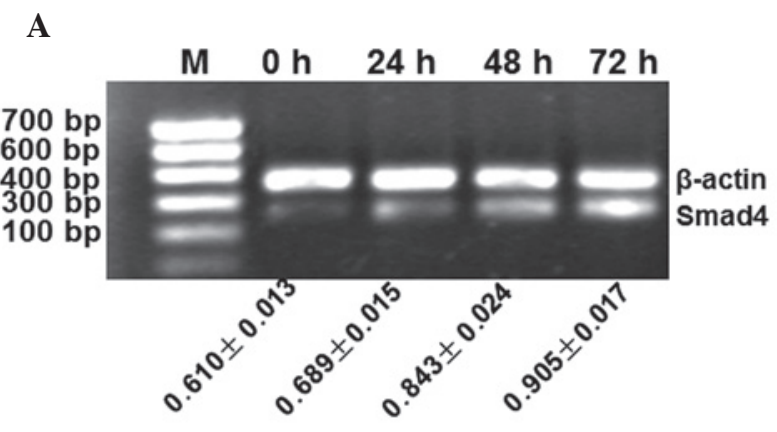

B

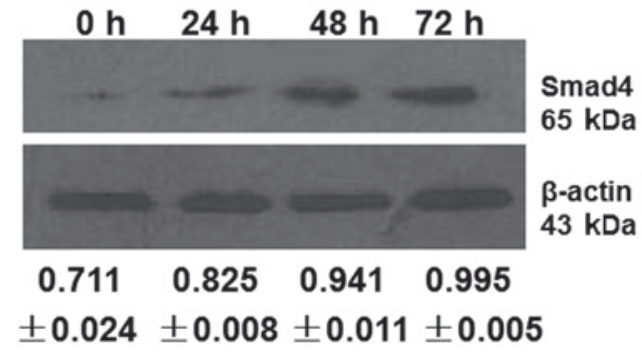

Figure 4. Analyses of Smad4 mRNA expression and protein expression. (A) RT-PCR analysis of Smad4 mRNA expression. T2 4 cells were untreated or treated with $0.02 \mathrm{mg} / \mathrm{ml} \beta$-elemene for 24,48 or $72 \mathrm{~h}$ and total RNA was extracted. The expression of Smad4 and $\beta$-actin mRNA was detected. M, Marker. (B) Western blot analysis of Smad4 protein expression. T24 cells were untreated or treated with $0.02 \mathrm{mg} / \mathrm{ml} \beta$-elemene for 24,48 or $72 \mathrm{~h}$ and total protein was extracted. The expression of Smad4 and $\beta$-actin proteins was detected.

$\beta$-elemene treatment upregulated Smad4 gene expression in T24 cells. We next sought to investigate how $\beta$-elemene functions in decreasing T24 cell survival. The expression of Smad 4 mRNA in untreated and $\beta$-elemene-treated T2 4 cells was detected by RT-PCR. The purity of the extracted mRNA was verified by agarose gel separation (Fig. 3). The expression levels of Smad4 mRNA increased gradually after 24, 48 and $72 \mathrm{~h}$ of treatment with $0.02 \mathrm{mg} / \mathrm{ml} \beta$-elemene $(\mathrm{P}<0.001$; Fig. 4A). The increase in Smad4 mRNA expression levels was significant in the treated T24 cells at each time-point compared with that in the untreated cells (LSD t-test, $\mathrm{P}<0.01$ ). Moreover, the expression levels of Smad4 mRNA in the T24 cells treated with $0.02 \mathrm{mg} / \mathrm{ml} \beta$-elemene were statistically significantly different between any two incubation time-points (SNK-q test, $\mathrm{P}<0.01$ ). These findings suggest that $0.02 \mathrm{mg} / \mathrm{ml}$ $\beta$-elemene upregulated the expression of Smad4 mRNA in the T24 bladder carcinoma cells significantly, and that the upregu- lation of Smad4 mRNA expression correlated positively with the incubation time.

Moreover, the expression of Smad4 protein in the T24 cells was detected by western blot analysis. The Smad4 protein was also upregulated in the T24 cells incubated with $0.02 \mathrm{mg} / \mathrm{ml}$ $\beta$-elemene for 24,48 and 72 h. $\left(F_{\text {time }}=249.89, P<0.001\right.$, Fig. $\left.4 \mathrm{~B}\right)$. Significant differences in protein expression levels were found at each time-point in cells treated with $\beta$-elemene compared with the control cells (LSD t-test, $\mathrm{P}<0.01$ ). The differences in protein expression levels were also statistically significant between any two treated groups of cells $(24,48$ or $72 \mathrm{~h}, \mathrm{SNK}-\mathrm{q}$ test, $\mathrm{P}<0.05)$. These findings indicate that $0.02 \mathrm{mg} / \mathrm{ml} \beta$-elemene upregulated the expression of Smad4 protein in T24 bladder carcinoma cells in a time-dependent manner. Therefore, we suspect that $\beta$-elemene may decrease the survival of T24 cells by upregulating the expression of the tumor suppressor gene Smad4.

\section{Discussion}

$\beta$-elemene is an active element extracted from Curcuma aromatica Salisb., a natural herb of the family Zingiberaceae. Due to of its strong effect in inhibiting tumor growth and proliferation, $\beta$-elemene is used in the treatment of lung cancer, malignancies of the alimentary tract and brain tumors, and an emulsion form of $\beta$-elemene has been designated as a class II noncytotoxic antitumor agent in China (10-12). A number of studies of the antitumor mechanism of $\beta$-elemene have been carried out during recent years, mainly concerning its ability to inhibit tumor vascularization, repair DNA damage and act as a sensitizer for radiotherapy (13-15). Since $\beta$-elemene is able to suppress the development of tumors significantly by inhibiting proliferation and inducing apoptosis $(16,17)$, previous studies concerning $\beta$-elemene have focused on its relationship with oncogenes, not on its relationship with tumor suppressor genes. Our study aimed to investigate the antitumor mechanism of $\beta$-elemene by monitoring the expression of a well-known tumor suppressor gene, Smad4, in $\beta$-elemene-treated T24 bladder carcinoma cells.

At present, the role of Smad4 in oncogenesis is of interest to numerous researchers. The antitumor effect of Smad4 depends on its potential to mediate the growth inhibition induced by TGF- $\beta$ (18). TGF- $\beta$ is able to inhibit the growth of epidermal cells, induce differentiation and maintain hereditary stability. The overexpression of TGF- $\beta$ in tumor cells may affect the tumor cells and their matrix, thereby inducing infiltration and metastasis and interfering with antitumor immunity $(19,20)$

Uncontrolled cell proliferation is the prerequisite of oncogenesis. Therefore, studies concerning tumor proliferation kinetics have been considered as the best approach for screening antitumor drugs or exploring their effects, since they may aid the understanding of the proliferation and metabolism of malignancies and elucidation of the mechanisms through which antitumor agents or physical/chemical factors act upon tumor cells. A number of studies have revealed the significant inhibition of tumor growth by $\beta$-elemene. A study carried out by Zhu et al (21) demonstrated that $\beta$-elemene inhibited the proliferation of the neuroblastoma cell line U87 and increased its sensitivity to cisplatin through activation of the GMF- $\beta$ pathway and inhibition of the phosphorylation of MKK3/6. It 
has also been reported by Chen et al (22) that $\beta$-elemene inhibited the growth and metastasis of melanoma by inhibiting the vascularization induced by vascular endothelial growth factor (VEGF). Another study by Zhu et al (23) revealed the effect of $\beta$-elemene in blocking the U87 glioma cell line at G0/G1 through its upregulation of P-MKK3 and P-MKK6 levels. Using an MTT assay, Li et al $(16,24)$ demonstrated the ability of $\beta$-elemene to repress the proliferation of the prostate cancer cell lines DU145 and PC-3, both of which are insensitive to androgen, and to improve the inhibitory effect of cisplatin in a time- and dose-dependent manner in the human non-small cell lung cancer (NSCLC) cell lines H460 and A549.

Our study evaluated the cytotoxic effects of $\beta$-elemene on T24 human bladder carcinoma cells by MTT assay, and revealed that the survival rate of the T2 4 cells decreased as the treatment duration and concentration of $\beta$-elemene increased, indicating that $\beta$-elemene inhibited the growth of the T24 cells in a time- and concentration-dependent manner. These results were in accordance with previous studies of other malignancies. The $\mathrm{IC}_{50}$ values of $\beta$-elemene in the $\mathrm{T} 24$ cells treated for 24, 48 and $72 \mathrm{~h}$ were calculated by SPSS software to be $0.015,0.010$ and $0.006 \mathrm{mg} / \mathrm{ml}$, respectively. A higher $\mathrm{IC}_{50}$ value for 24 than $48 \mathrm{~h}$ suggests that a low concentration $\beta$-elemene treatment may achieve the same inhibitory effect as a high concentration treatment if the incubation time is long enough. Our results indicate that the inhibition of the growth and proliferation of T24 human bladder carcinoma cells by $\beta$-elemene may be one of the key mechanisms against cancer.

In our study, after treatment with $0.02 \mathrm{mg} / \mathrm{ml} \beta$-elemene for 24 to $72 \mathrm{~h}$, the T24 cells appeared to be suspended when subjected to microscopic observation. Some cells became round, elliptical or irregular in shape, with weakened light refraction and attachment ability. Those cells had a tendency for suspended growth, and a few became round and detached from the well. Some cells even collapsed into fragments and apoptotic bodies were observed along the surface of cell membrane after $48 \mathrm{~h}$ of treatment. These findings further support the ability of $\beta$-elemene to induce the apoptosis of bladder cancer cells.

The development of tumors is complicated, involving multiple genes, procedures and stages. Abnormality in apoptosis correlates closely with oncogenesis, tumor development and metastasis. $\beta$-elemene has the ability to kill malignant cells and inhibit the growth of neoplasms. Liu et al (25) found that $\beta$-elemene induced the apoptosis of A49 human NSCLC cells by inhibiting the activity of the PI3K/Akt/mTOR/p70S6K1 pathway. Li et al (26) revealed that $\beta$-elemene induced apoptosis in A549 human NSCLC cells in a time- and dosedependent manner. A study by Ying et al (27) indicated that $\beta$-elemene may induce the apoptosis of HL-60 human leukemia cells by releasing cytochrome $\mathrm{c}$ and other apoptosis inducers to the cytoplasm as well as by translocating Bax from the cytoplasm to mitochondria, and this induction appeared to be time-dependent. However, the mechanism by which $\beta$-elemene inhibits tumors is not fully clear.

Furthermore, the expression levels of the Smad4 gene were upregulated by $0.02 \mathrm{mg} / \mathrm{ml} \beta$-elemene in a time-dependent manner. The expression levels of Smad4 following 24, 48 and $72 \mathrm{~h}$ of treatment were analyzed by RT-PCR and western blot analysis, and the results revealed the elevated levels of
mRNA and protein. Since the upregulation of expression was correlated closely with the time of $\beta$-elemene treatment, it is speculated that expression of Smad4 also correlated with the concentration of $\beta$-elemene, which requires further investigation. These findings suggest that Smad4 functions by regulating the proliferation of bladder cancer cells, which results in the repression of proliferation and the induction of apoptosis.

In conclusion, we found that $\beta$-elemene inhibits the growth and proliferation of bladder cancer cells significantly, in a time- and concentration-dependent manner. Microscopic observation also revealed the potential of $\beta$-elemene to induce the apoptosis of cancer cells. Moreover, $\beta$-elemene was able to increase the expression levels of Smad4, a tumor suppressor gene, in T24 human bladder carcinoma cells, in a time-dependent manner. These results suggest that the upregulation of Smad4 gene expression may be one of the antitumor mechanisms of $\beta$-elemene and provide a theoretical basis for the treatment of bladder cancer. Further studies are required to elucidate the influence of $\beta$-elemene on other oncogenes, tumor suppressor genes and genes associated with apoptosis.

\section{Acknowledgements}

This study was supported by the Hunan Provincial Natural Scientific Research Fund (Grant Number, 2010851012154355).

\section{References}

1. Xie T, Hua BJ and Sun M: Clinical progression in $\beta$-elemene research. Chin J Clin Oncol 36: 22, 2009 (In Chinese).

2. Adio AM: (-)-trans- $\beta$-Elemene and related compounds: occurrence, synthesis, and anticancer activity. Tetrahedron 65: 5145-5159, 2009.

3. Damstrup L, Rygaard K, Spang-Thomsen M and Skovgaard Poulsen $\mathrm{H}$ : Expression of transforming growth factor beta (TGF beta) receptors and expression of TGF beta 1, TGF beta 2 and TGF beta 3 in human small cell lung cancer cell lines. Br J Cancer 67: 1015-1102, 1993.

4. Gordon KJ and Blobe GC: Role of transforming growth factor-beta superfamily signaling pathways in human disease. Biochim Biophys Acta 1782: 197-228, 2008.

5. Kamiya Y, Miyazono K and Miyazawa K: Smad7 inhibits transforming growth factor-beta family type I receptors through two distinct modes of interaction. J Biol Chem 285: 30804-30813, 2010.

6. Yang $X$ and Zhang YG: Research progress in relationship between Smads and organ fibrosis. Medical Recapitulate 17: 11, 2011 (In Chinese).

7. $\mathrm{Li} \mathrm{ZZ}$ and $\mathrm{Li} \mathrm{Q}$ : TGF- $\beta /$ Smads signal pathway and its role in tumor. Medical Recapitulate 17: 6, 2011 (In Chinese).

8. Lagna G, Hata A, Hemmati-Brivanlou A, et al: Partnership between DPC4 and SMAD proteins in TGF-beta signalling pathways. Nature 383: 832-836, 1996.

9. Cao B, Jiang MC, Lei ZY, et al: Effects of PLAB on apoptosis and Smad signal pathway of hypertrophic scar fibroblasts. J Asian Nat Prod Res 10: 147-157, 2008.

10. Li GQ, Xie BB, Chen YH, Li XL and Zou LJ: A research on adiotherapy sensitization by $\beta$-elemene on human adenocarcinoma implanted in naked mice and its correlation with HIF-1 $\alpha$ CAIX. Chin J Clin Oncol 38: 6, 2011 (In Chinese).

11. Liu J, Lo ZH, Liu YP, Qu XJ, Hou KZ, Xu L and Zhang Y: Influence of $\beta$-elemene on apoptosis of gastric cancer MGC803 cells and the mechanism. Shandong Medical Journal 37: 7, 2010 (In Chinese).

12. Gao $\mathrm{C}$ and $\mathrm{Wu} \mathrm{R}$ : A meta-analysis on $\beta$-elemene in single dosage or combination with chemotherapy/radiotherapy to treat brain malignancies. Chin J Clin Oncol 37: 7, 2010 (In Chinese).

13. Li GQ, Xie BB, Chen YH, Li XL and Zou LJ: A research on correlation between radiotherapy sensitized by $\beta$-elemene and tumor vascularization. The Practical Journal of Cancer 26: 1, 2011 (In Chinese). 
14. Li LJ, Zou LJ, Zhang Z and Wang Q: The effect of $\beta$-elemene combined with radiation on DNA damage and repair in A549 cells. Chinese Journal of Radiation Oncology 20: 355-357, 2011 (In Chinese)

15. Li GQ, Li XL, Xie BB, Chen YH, Lei HW and Zou LJ: Study on the radiosensitivity of nude mice model transplanted lung adenocarcinoma cell treated by $\beta$-elemene. Chinese Journal of Radiological Medicine and Protection 30: 687-691, 2010 (In Chinese).

16. Li QQ, Wang G, Huang F, Banda M and Reed E: Antineoplastic effect of beta-elemene on prostate cancer cells and other types of solid tumour cells. J Pharm Pharmacol 62: 1018-1027, 2010.

17. Zhan YH, Liu ZY, Liu J, Liu YP, Qu XJ, Hou KZ and Wu B: An exploration on $\beta$-elemene influence of on kidney cancer 786-0 cells and its mechanism. Shandong Medical Journal 51: 30, 2011 (In Chinese)

18. Samanta D and Datta PK: Alterations in the Smad pathway in human cancers. Front Biosci 17: 1281-1293, 2012.

19. Lampropoulos P, Zizi-Sermpetzoglou A, Rizos S, et al: TGF-beta signalling in colon carcinogenesis. Cancer Lett 314: $1-7,2012$.

20. Kretschmer C, Conradi A, Kemmner W and SternerKock A: Latent transforming growth factor binding protein 4 (LTBP4) is down regulated in mouse and human DCIS and mammary carcinomas. Cell Oncol (Dordrecht) 34: 419-434, 2011.
21. Zhu T, Xu Y, Dong B, Zhang J, Wei Z, Xu Y and Yao Y: $\beta$-elemene inhibits proliferation of human glioblastoma cells through the activation of glia maturation factor $\beta$ and induces sensitization to cisplatin. Oncol Rep 26: 405-413, 2011.

22. Chen WX, Lu Y, Wu JM, Gao M, Wang AY and Xu B: Beta-elemene inhibits melanoma growth and metastasis via suppressing vascular endothelial growth factor-mediated angiogenesis. Cancer Chemother Pharmacol 67: 799-808, 2011.

23. Zhu TZ, Zhao YS, Zhang JN, Li LJ, Zou LJ, Yao YQ and Xu YH: $\beta$-Elemene inhibits proliferation of human glioblastoma cells and causes cell-cycle G0/G1 arrest via mutually compensatory activation of MKK3 and MKK6. Int J Oncol 38: 419-426, 2011.

24. Li QQ, Wang G, Zhang M, Cuff CF, Huang L and Reed E: beta-Elemene, a novel plant-derived antineoplastic agent, increases cisplatin chemosensitivity of lung tumor cells by triggering apoptosis. Oncol Rep 22: 161-170, 2009.

25. Liu J,Hu XJ, Jin B, Qu XJ, Hou KZ and Liu YP: $\beta$-Elemene induces apoptosis as well as protective autophagy in human non-small-cell lung cancer A549 cells. J Pharm Pharmacol 64: 146-153, 2012.

26. Li L, Xu L, Qu XJ, et al: Cbl-regulated Akt and ERK signals are involved in $\beta$-elemene-induced cell apoptosis in lung cancer cells. Mol Med Rep 4: 1243-1246, 2011.

27. Ying J, Yang W, Xie CY, et al: Induction of caspase-3-dependent apoptosis in human leukemia HL-60 cells by $\delta$-elemene. Yakugaku Zasshi 131: 1383-1394, 2011. 